\title{
Helmintoses intestinais em população de rua da cidade do Rio de Janeiro
}

\author{
Intestinal helminthiasis in street population of Rio de Janeiro city \\ Tatiana C. Gomes', Monique F. Almeida1, Lina A. Miura1', Jeferson Granja', Desirée V.G. Santos ${ }^{1}$, \\ Rejane M.F. Oliveira', Alexandre Lopes' ${ }^{1}$, Bruno P. Sequeira ${ }^{1}$, Alessandro A. Rolemberg', \\ Ana L. Moraes ${ }^{1}$ e Carlos S. Santos ${ }^{1}$
}

Resumo Em 82 exames parasitológicos de fezes realizados pelo método de sedimentação espontânea, em indivíduos moradores em ruas da Cidade do Rio de Janeiro, foram encontrados ovos de Ascaris lumbricoides em 40 (48,8\%), de Trichuris trichiura em 27 (32,9\%) e ancilostomídeos 7 (8,5\%).

Palavras-chaves: Helmintoses intestinais. Geo-helmintoses. Inquérito coproscópico. Ascaris lumbricoides. Trichuris trichiura. Ancilostomídeos.

Abstract Stool examination by sedimentation method in 82 homeless individuals living in the streets of Rio de Janeiro City, revealed Ascaris lumbricoides eggs in 40 (48.85\%), Trichuris trichiura in 27 (32.9\%) and hookworm in 7 (8.5\%).

Key-words: Intestinal helminthiasis. Geohelminth. Parasitological survey. Ascaris lumbricoides. Trichuris trichiura. Hookworm.

A cidade do Rio de Janeiro, a exemplo de outras grandes cidades, possui uma população que habita as ruas e é sistematicamente recolhida aos abrigos da Secretaria Municipal de Desenvolvimento Social (SMDS). Embora vários estudos tenham sido realizados no sentido de estabelecer a prevalência das helmintoses intestinais em populações carentes, as populações de rua não vêm sendo estudadas com a mesma ênfase.

Neste trabalho estudamos a prevalência de Ascaris lumbricoides, Trichuris trichiura e ancilostomídeos na população moradora de vias públicas e recolhida aos abrigos públicos, hoje estimada em cerca de 800 pessoas, segundo os dados fornecidos pela Secretaria Municipal de Desenvolvimento Social da Prefeitura da Cidade do Rio de Janeiro.

Foram coletadas amostras de fezes de 82 indivíduos em 8 abrigos da SMDS localizados nos bairros de Vila Isabel (três abrigos), Centro, Catete, Leblon, Realengo e llha do Governador do município do Rio de Janeiro, no período de julho de 1997 a dezembro de 1998. Na mesma ocasião, foi preenchida uma ficha inquérito para cada caso, na qual constavam dados sobre o local freqüentado pelo indivíduo, o local onde foi recolhido pela SMDS, o tempo de moradia nas ruas, o hábito de defecar ou não nas ruas, as atividades de trabalho por ventura exercidas, dados referentes à alimentação e higiene, além de itens referentes à identificação (nome, idade, escolaridade, família, etc).

O material fecal foi coletado e conservado em potes contendo MIF modificado ${ }^{1}$ e a seguir levado para a Disciplina de Parasitologia da Escola de Medicina da Fundação Técnico-Educacional Souza Marques, onde as amostras foram homogeneizadas e filtradas para cálices de sedimentação, sendo completado o volume com água e deixado a sedimentar por duas horas. Cada sedimento foi examinado microscopicamente por dois observadores de forma independente.

Dado que o material estava conservado em MIF, realizamos um pré-teste no qual foram utilizados fezes de cães, para avaliar a sensibilidade para a detecção de ovos de ancilostomídeos através da metodologia de sedimentação utilizada e concluímos que o método proposto apresentava resultados similares ao método de Willis para a pesquisa de ovos de ancilostomídeos.

\footnotetext{
1. Disciplina de Parasitologia da Escola de Medicina da Fundação Técnico-Educacional Souza Marques, Rio de Janeiro, RJ, Brasil. Os autores deste trabalho são monitores/estagiários da Disciplina de Parasitologia, à exceção do último, que é Professor

Endereço para correspondência: Dr. Carlos Silveira Santos. R. Catete 6, Catete, 22220-000 Rio de Janeiro, RJ.

Tel: 5521 2509-2134

e-mail: silveirasantos@uol.com.br

Recebido para publicação em 03/07/2001
} 
Dentre os 82 indivíduos estudados, 61 eram do sexo masculino e 21 do sexo feminino, com as idades variando entre 9 meses e 46 anos ( Tabela 1). Foi observado maior número de indivíduos na faixa etária entre 11 e 17 anos que, segundo dados da SMDS - RJ, é a de maior prevalência nesta população moradora de vias públicas

A Tabela 2 mostra a positividade dos exames de fezes, em relação ao mono e poliparasitismo. Observouse que $52(63,4 \%)$ casos eram positivos e $30(36,6 \%)$ negativos, estando as maiores prevalências de positividade na população de 11 a 17 anos de idade.
Nos casos de poliparasitismo, houve maior freqüência da associação de Ascaris lumbricoides e Trichuris trichiura (13 (16\%) casos ).

A faixa etária de 14 a 15 anos apresentou percentual mais elevado de parasitismo por Ascaris_lumbricoides com $16(19,5 \%)$ casos, seguida das faixas etárias 11 a 13 e 16 a 17 anos. No caso de Trichuris trichiura, as maiores prevalências foram no grupo etário de 11 a 17 anos. Em relação aos ancilostomídeos, as prevalências encontradas foram sempre mais baixas e distribuídas de forma similar dos 6 aos 17 anos de idade (Tabela 3).

Tabela 1- Distribuição dos 82 moradores de rua do Rio de Janeiro, segundo faixa etária e sexo.

\begin{tabular}{lccccccc}
\hline Sexo & \multicolumn{9}{c}{ Idade (anos) } & \multicolumn{2}{c}{ Total } \\
\cline { 2 - 7 } & até 5 & 6 & 11 & 14 & 16 & $18-46$ & - \\
\hline Masculino & 1 & 10 & 11 & 25 & 11 & 3 & 61 \\
Feminino & 2 & 1 & 4 & 3 & 5 & 6 & 21 \\
\hline Total & 3 & 11 & 15 & 28 & 16 & 9 & 82 \\
\hline
\end{tabular}

Tabela 2 - Positividade dos exames de fezes em 82 moradores de rua do Rio de Janeiro, em relação à idade e ao mono e poliparasitismo.

\begin{tabular}{|c|c|c|c|c|c|c|c|c|}
\hline \multirow[b]{2}{*}{ Exames de fezes } & \multicolumn{6}{|c|}{ Idade (anos) } & \multicolumn{2}{|c|}{ Total } \\
\hline & até 5 & $6-10$ & $11-13$ & $14-15$ & $16-17$ & $18-46$ & $n^{\circ}$ & $\%$ \\
\hline Negativo & 1 & 6 & 5 & 9 & 5 & 4 & 30 & 36,6 \\
\hline Monoparasitismo & 1 & 4 & 4 & 13 & 6 & 3 & 31 & 37,9 \\
\hline Poliparasitismo & 1 & 1 & 6 & 6 & 5 & 2 & 21 & 25,5 \\
\hline Total & 3 & 11 & 15 & 28 & 16 & 9 & 82 & 100,0 \\
\hline
\end{tabular}

Tabela 3 - Exame de fezes em 82 moradores de rua do Rio de Janeiro, em relação à idade e ovos de helmintos.

\begin{tabular}{|c|c|c|c|c|c|c|c|c|}
\hline \multirow[b]{2}{*}{ Helmintos } & \multicolumn{6}{|c|}{ Idade (anos) } & \multicolumn{2}{|c|}{ Total } \\
\hline & até 5 & $6-10$ & $11-13$ & $14-15$ & $16-17$ & $18-46$ & $\mathrm{n}^{\circ}$ & $\%$ \\
\hline Ascaris lumbricoides & 1 & 4 & 8 & 16 & 7 & 4 & 40 & 48,8 \\
\hline Trichuria trichiura & 1 & 2 & 8 & 7 & 6 & 3 & 27 & 32,9 \\
\hline Ancilostomídeos & 0 & 1 & 1 & 2 & 3 & 0 & 7 & 8,5 \\
\hline
\end{tabular}

Em um dos abrigos estudados, os indivíduos eram tratados indiscriminadamente com anti-helmínticos tão logo ali chegavam. Neste abrigo, o resultado inverteuse, apresentando $73 \%$ de casos negativos contra $27 \%$ de positivos.

Com relação aos hábitos pessoais relatados durante as entrevistas observou-se que 59 (72\%) dos indivíduos tinham contato freqüente com o solo, por andarem descalços e deitarem em áreas de terra de praças, jardins e praias. Quanto ao local para defecação, 34 $(41,46 \%)$ dos entrevistados afirmaram utilizar as vias públicas para este fim, incluindo ruas, praças e praias, sendo que neste grupo observou-se 21 casos de positividade para algum dos parasitas detectados. Dos 34 indivíduos que utilizavam as vias públicas para defecação, 1 (3\%) pertencia a faixa etária de 6 a 10 anos, $10(29,4 \%)$ estavam na faixa de 11 a 13 anos, 12 $(35,2 \%)$ na faixa de 14 a 15 anos, $7(20,6 \%)$ de 16 e 17 anos e $4(11,8 \%)$ com 18 anos ou mais.

Quanto às atividades de trabalho, 20 indivíduos $(24,3 \%)$ relataram exercer algum tipo de trabalho nas ruas, dentre os quais $7(8,5 \%)$ referiram atividades que envolvem alimentos.

O estudo parasitológico das chamadas populações de rua tem muita importância, não apenas pelo fato de avaliar-se seu estado de saúde e condições sanitárias, como pelo seu potencial de contaminação de logradouros públicos com formas de transmissão de parasitas.

A reunião em grupos nas ruas, dividindo os alimentos, utensílios e espaços para dormir poderia facilitar a circulação dos enteroparasitas entre estes indivíduos.

\section{REFERÊNCIA BIBLIOGRÁFICA}

1. Ferreira LF, Morteo RE, Rodrigues da Silva J. Padronização de técnicas para exame parasitológico de fezes. Jornal Brasileiro de Medicina (Rio de Janeiro) 6 : 252-257, 1962. 